\title{
The effects of serum TC, HDL, APOA-I levels on the prognosis of sepsis patients
}

\author{
T Zhang ${ }^{1}$, L Tong ${ }^{2}$ C C Cai ${ }^{2 *}$ \\ From ESICM LIVES 2015 \\ Berlin, Germany. 3-7 October 2015
}

\section{Introduction}

Cholesterol (total cholesterol, TC) as the part of the fat plays an important role in maintaining the integrity of cell membrane and generating certain of steroids as well as fat-soluble vitamins. Therefore, low levels of cholesterol in patients with sepsis maybe have adverse effects $[1,2]$. Some studies have showed that high-density lipoprotein (HDL), apolipoprotein A-I (apoA-I) seem to be associated with the risk of infection by neutralizing the lipopolysaccharide(LPS) which was the most critical initiation factor in septic shock $[3,4]$.

\section{Objectives}

To observe the relationship between the levels of total cholesterol (TC), high-density lipoprotein (HDL), apolipoprotein A-I (apoA-I) and the severity of sepsis. To analysis these markers' predictive value for sepsis.

\section{Methods}

This is an retrospective observational study. A total of 37 patients hospitalized in the surgery intensive care unit of the Third Affiliated Hospital of Sun Yat-Sen University from December 2013 to December 2014 were enrolled in the study. All patients were divided into two groups according to the status after 28 days. The correlations between the lipoprotein and inflammatory cytokines, the independent predictive factors for sepsis were analyzed. Receiver-operating-characteristic curve (ROC) was used to evaluate the cut-off of TC, HDL, apoA-1 and APACH II as well as their predictive value for 28days mortality.

\section{Results}

There was negative correlation between HDL, TC, apoA- 1 and tumor necrosis factor- $\alpha(\mathrm{TNF}-\mathrm{a})$, interleukin

${ }^{2}$ The 1st Affiliated Hospital, Sun Yat-Sen University, Guangzhou, China

Full list of author information is available at the end of the article
(IL-6) separately. Whereas these lipoprotein indexes didn't have significant correlation with neutrophil. The cut-off point of TC, HDL, apoA-I, APACHEII score were $1.46 \mathrm{mmol} / \mathrm{l}, 0.175 \mathrm{mmol} / \mathrm{l}, 0.525 \mathrm{~g} / \mathrm{l}, 20.5$ points. apoA-I has the highest diagnostic and predictive value.

\section{Conclusions}

The levels of TC, HDL, apoA-I can reflect the degree of inflammatory response to the sepsis and the severity of the disease. TC, HDL, apoA-I, APACHEII within 24 hours of sepsis have predictive value. But apoA-I was the highest diagnostic one.

\section{Grant Acknowledgment}

Thanks Mrs Tong to collect the data, recruit the cases.

\section{Authors' details}

${ }^{1}$ Guangzhou First People's Hospital, Guangzhou, China. ${ }^{2}$ The 1st Affiliated Hospital, Sun Yat-Sen University, Guangzhou, China.

Published: 1 October 2015

\section{References}

1. Canturk NZ, Canturk Z, Okay E, et al: Risk of nosocomial infections and effects of total cholesterol, HDL cholesterol in surgical patients. Clin Nutr 2002, 21(5):431-436.

2. Dunham CM, Fealk MH, Sever WR: Following severe injury, hypocholesterolemia improves with convalescence but persists with organ failure or onset of infection. Crit Care 2003, 7(6):R145-R153.

3. Ulevitch RJ, Johnston AR, Weinstein DB: New function for high density lipoproteins. Isolation and characterization of a bacterial lipopolysaccharide-high density lipoprotein complex formed in rabbit plasma. J Clin Invest 1981, 67(3):827-837.

4. Levine DM, Parker TS, Donnelly TM, et al: In vivo protection against endotoxin by plasma high density lipoprotein. Proc Natl Acad Sci U S A 1993, 90(24):12040-12044.

doi:10.1186/2197-425X-3-S1-A874

Cite this article as: Zhang et al:: The effects of serum TC, HDL, APOA-I

levels on the prognosis of sepsis patients. Intensive Care Medicine Experimental 2015 3(Suppl 1):A874. (c) 2015 Zhang et al.; This is an Open Access article distributed under the terms of the Creative Commons Attribution License (http:// creativecommons.org/licenses/by/4.0), which permits unrestricted use, distribution, and reproduction in any medium, provided the original work is properly cited. 